\title{
Electrical Injury and Wandering Atrial Pacemaker
}

\author{
Ranjan K. Singh ${ }^{1}$
}

1. Internal Medicine, Anti-Retroviral Therapy Centre, District Hospital, Khagaria, IND

Review began 09/21/2021 Review ended 09/23/2021 Published 09/27/2021

๑) Copyright 2021

Singh. This is an open access article distributed under the terms of the Creative Commons Attribution License CC-BY 4.0., which permits unrestricted use, distribution, and reproduction in any medium, provided the original author and source are credited.

Corresponding author: Ranjan K. Singh, dr_ranjankumarsingh@yahoo.com

\begin{abstract}
The supply of household electricity remains a low-voltage (110-220 V) energy source, and its effects on the human body depend on several factors, including the type of contact and duration of contact, among other things. In a significant number of cases, direct contact with household electricity causes reversible cardiac arrhythmia-ventricular fibrillation, ventricular premature beats, atrial tachycardia, and atrial fibrillation.
\end{abstract}

Wandering atrial pacemaker (WAP) is a benign atrial arrhythmia observed in elderly patients suffering from obstructive pulmonary diseases that result from an ischemic heart. This report discusses WAP as observed in a patient who suffered an electrical injury.

Categories: Cardiology, Medical Physics, Trauma

Keywords: wandering atrial pacemaker, voltage, electrical injury, arrhythmia, ampere

\section{Introduction}

The effects of electrical injury vary from skin burn to internal organ damage directed especially at the cardiovascular and nervous systems. The extent of electrical injury depends on the type of electricity source, i.e., direct current (DC) or alternating current (AC), the duration of contact with the source of electricity, the state of the body whether wet or dry, the presence of calluses over the palm, the route of electrical flow, and the level of voltage [1]. The severity of an electric shock depends on the current flow (I) measured in ampere (A). It is linked to the resistance of the conductor ( $\mathrm{R}$, unit: ohm ' $\mathrm{W}$ ') and the potential difference between the two ends of a conductor (Volt; unit V), and is derived by applying the formula based on Ohm's law: i.e., I $=\mathrm{V} / \mathrm{R}$. The severity of an electrical burn, by contrast, depends on the energy (Watt) and is derived from Joule's formula W=I2 x R x T (duration of exposure with the source of current).

Household electrical supply is a low-voltage $(220 \mathrm{~V}) \mathrm{AC}$ at $60 \mathrm{~Hz}$ frequency. The physiological effects of contact with a low-frequency $\mathrm{AC}(60 \mathrm{~Hz})$ current vary at different amperes. For example, $1 \mathrm{~mA}(1 / 1000 \mathrm{~A})$ is barely perceptible as numbness, whereas $20 \mathrm{~mA}$ can cause respiratory muscle paralysis, while $100 \mathrm{~mA}$ reaches a threshold for ventricular fibrillation $[1,2]$. The resulting cardiac arrhythmia may take the form of ventricular fibrillation, ventricular tachycardia, ventricular premature beats, atrial premature beats, atrial arrhythmia, and/or heart block [2].

\section{Case Presentation}

A 40-year-old male patient was brought into the emergency ward after suffering an accidental electrical injury that involved an entry wound in the middle of his left hand and an exit wound in the back of his chest. He was holding the hanging rod for a ceiling fan when the connection was plugged in, resulting in electric shock. He lost consciousness and fell to the ground with the rod clenched in his hand for a minute and a half. The electricity source was disconnected and cardiopulmonary resuscitation was administered to the patient by his neighbors. The patient regained consciousness and complained of aching all over the body along with general weakness.

He had a black hole in the middle of his left palm (Figure $1 A$ ) and a linear burn on the back of his chest (Figure 1B). 


\section{Cureus}

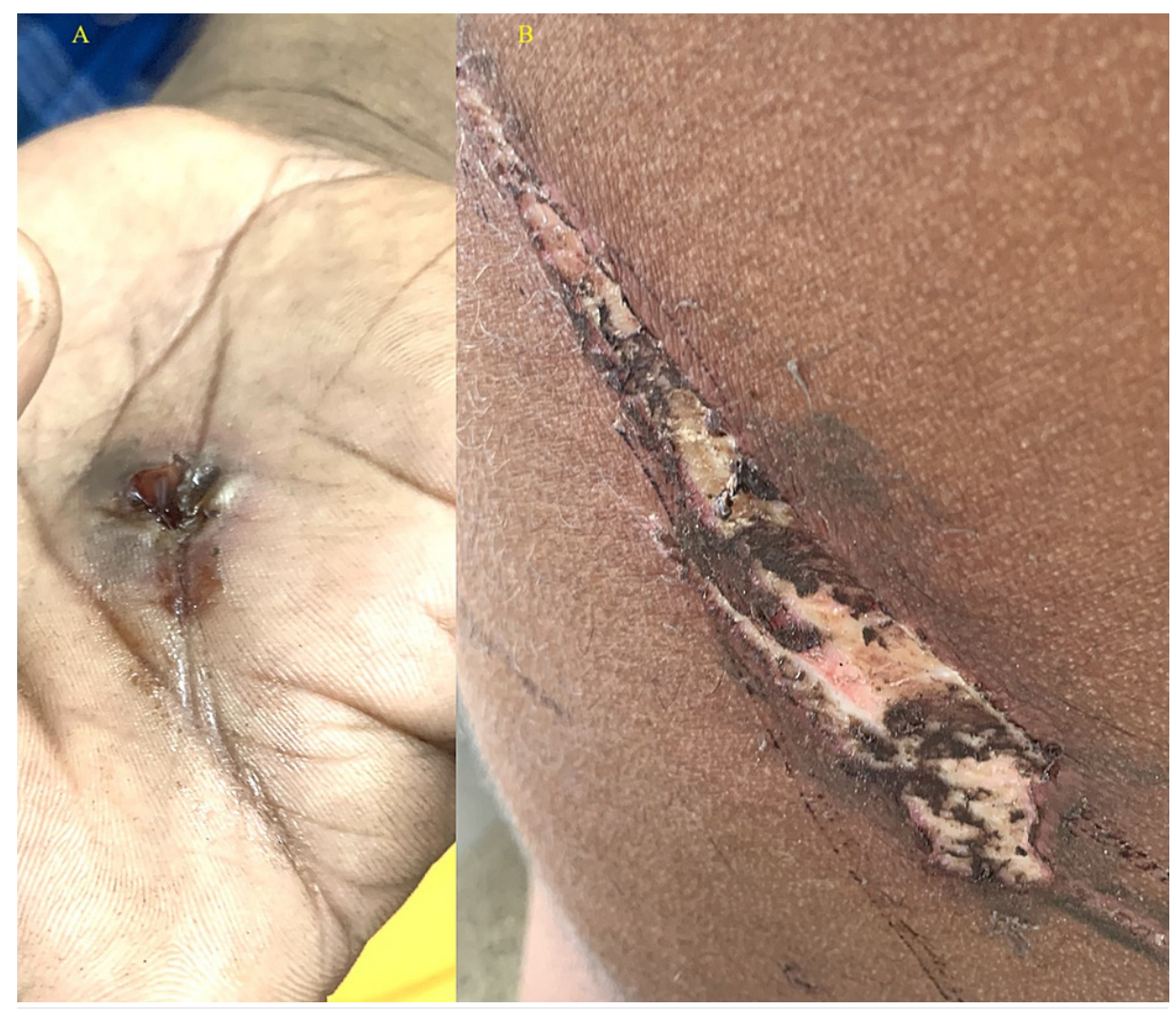

FIGURE 1: Entry wound (panel A) and exit wound (panel B).

His pulse was irregularly irregular at 78/minute, and his blood pressure was $110 / 78 \mathrm{~mm} \mathrm{Hg}$. His total leucocyte count was $8600 / \mathrm{cmm}$ with neutrophils at $64 \%$, and his hemoglobin was $13 \mathrm{gm} / \mathrm{dL}$. Urinalysis did not show myoglobin. Serum sodium and potassium were $134 \mathrm{mEq} / \mathrm{L}$ and $4.2 \mathrm{mEq} / \mathrm{L}$, respectively.

Electrocardiography (ECG) showed occasional ventricular premature beat with wandering atrial pacemaker (Figures $2 A-2 B$ ). Of note, the patient did not have any kind of cardiac ailment previously. The patient was hydrated with intravenous fluids and his wounds were treated with antiseptic dressings and antibiotics. He remained under observation for 48 hours and the ECG showed sinus rhythm (Figure 2C). 


\section{Cureus}

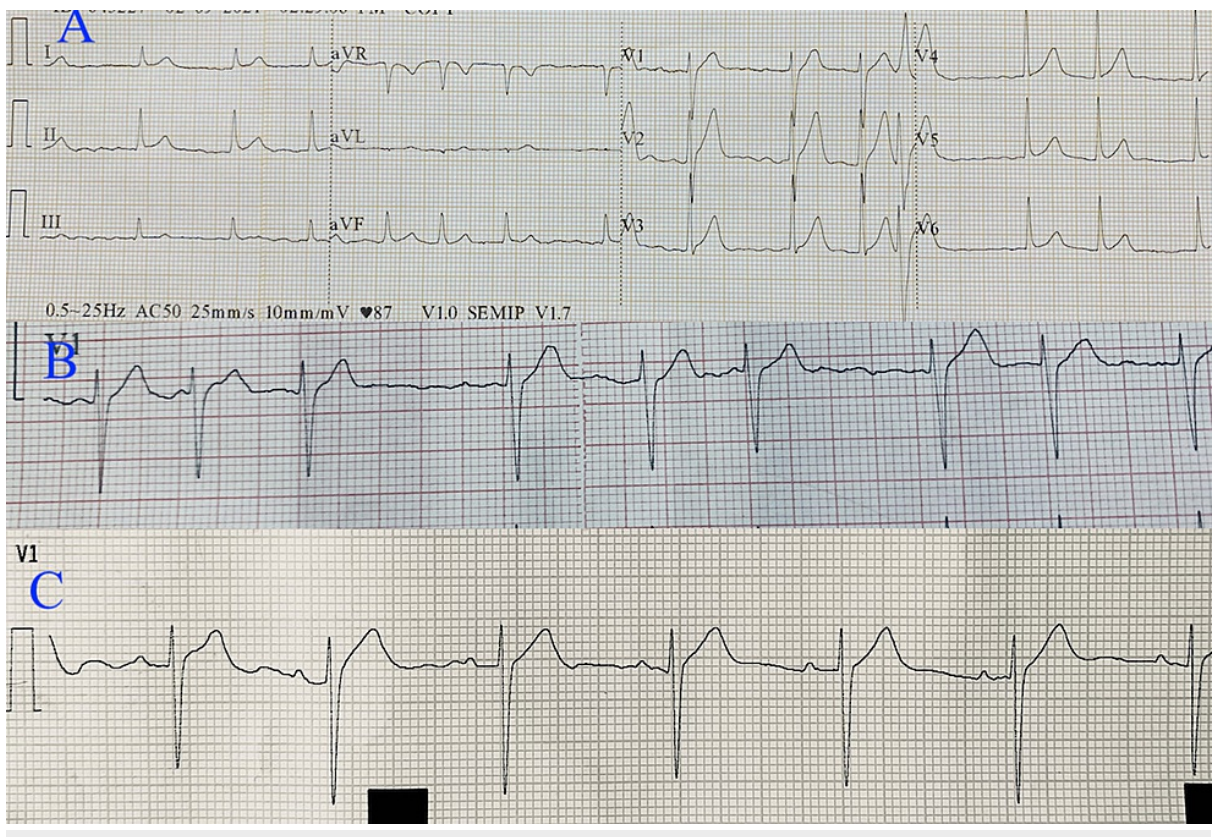

FIGURE 2: Panel A shows the ventricular premature beat in V1-3, panel B shows wandering atrial pacemaker, and panel $\mathrm{C}$ shows sinus rhythm.

\section{Discussion}

Low voltage currents cause severe electrical burns to the skin as a result of high energy output from the current flow. Dry skin with callouses over palm (resistance of $500 \mathrm{~W}$ ) and a long contact of palm with the source of electricity attribute to severe burn in this patient (Joule formula). Thereby, the electrical energy output is dissipated and there is less internal injury $[3,4]$.

Low voltage currents travel through the body along low-resistance pathway nerves and blood vessels to cause severe cardiac injury. Also, the distance between the entry and exit wounds can determine the severity of the cardiac injury. The heart remains in the central location of the electrical current's pathway between the left palm and back of the chest. Current spikes occur in the palm and fingers of an individual holding a metal rod that is suddenly connected to an electric source [5]. The electric shock causes depolarisation of cardiac muscles and increases membrane pores of the cells resulting in arrhythmias; sinus tachycardia, ventricular premature beats, ventricular tachycardia, and atrial fibrillation are common [6,7]. Wandering atrial pacemaker (WAP) is a benign atrial arrhythmia that has been observed in this case study. WAP and multifocal atrial tachycardia (MAT) differ only with the heart rate - WAP has a heart rate less than $100 \mathrm{bpm}$ whereas MAT has a heart rate greater than $100 \mathrm{bpm}$. In the WAP rhythm, the pacemaker wanders with the impulses originating from the sinoatrial node to the atrium, and to the atrioventricular junction with a changing focus. Hence, the P waves on an ECG are presented in different configurations. WAP is differentiated from sinus arrhythmia by the fact that heart rate variability occurs from beat-to-beat, and is not phasic. Also, in sinus arrhythmia, the P-wave morphology and the P-R interval are constant [7]. Most of the arrhythmias occur soon after electric shock and are short-lived. However, delayed arrhythmias occurring 12 hours after electric shock have been reported, too [8].

\section{Conclusions}

Household electric supply is low voltage AC of $60 \mathrm{~Hz}$. It is the electric current that determines the pathophysiological effects in the body but the voltage does determine the outcome of electric shock. Even a low-voltage shock can cause ventricular fibrillation if resistance is low and current flow reaches a threshold of $100 \mathrm{~mA}$. The severity of burn lesion is determined by the resistance of skin and duration of exposure with the source of current. Most cardiac arrhythmias are short-lived and do not require treatment.

\section{Additional Information}

\section{Disclosures}

Human subjects: Consent was obtained or waived by all participants in this study. NA issued approval NA. This is a case report. Conflicts of interest: In compliance with the ICMJE uniform disclosure form, all authors declare the following: Payment/services info: All authors have declared that no financial support was received from any organization for the submitted work. Financial relationships: All authors have declared that they have no financial relationships at present or within the previous three years with any 


\section{Cureus}

organizations that might have an interest in the submitted work. Other relationships: All authors have declared that there are no other relationships or activities that could appear to have influenced the submitted work.

\section{References}

1. Waldmann V, Narayanan K, Combes N, Jost D, Jouven X, Marijon E: Electrical cardiac injuries: current concepts and management. Eur Heart J. 2018, 39:1459-1465. 10.1093/eurheartj/ehx142

2. Waldmann V, Narayanan K, Combes N, Marijon E: Electrical injury. BMJ. 2017, 357:j1418 10.1136/bmj.j1418

3. Dixon GF: The evaluation and management of electrical injuries . Crit Care Med. 1983, 11:384-387. 10.1097/00003246-198305000-00015

4. Pawlik AM, Lampart A, Stephan FP, Bingisser R, Ummenhofer W, Nickel CH: Outcomes of electrical injuries in the emergency department: a 10-year retrospective study. Eur J Emerg Med. 2016, 23:448-454. 10.1097/MEJ.0000000000000283

5. Fish RM, Geddes LA: Electrophysiology of connection current spikes . Cardiovasc Eng. 2008, 8:219-224. 10.1007/s10558-008-9059-7

6. Kastor JA: Multifocal atrial tachycardia. N Engl J Med. 1990, 322:1713-1717. 10.1056/NEJM199006143222405

7. Bhattad PB, Jain V: Changing P wave morphology-a focus on multifocal atrial tachycardia . J Med Res. 2020 6:109-111.

8. Jensen PJ, Thomsen PE, Bagger JP, Nørgaard A, Baandrup U: Electrical injury causing ventricular arrhythmias. Br Heart J. 1987, 57:279-283. 10.1136/hrt.57.3.279 